\title{
Analysis of bi-directional piezoelectric-based converters for zero-voltage switching operation
}

Ekhtiari, Marzieh; Zhang, Zhe; Andersen, Michael A. E.

Published in:

IEEE Transactions on Power Electronics

Link to article, DOI:

10.1109/TPEL.2016.2537820

Publication date:

2016

Document Version

Peer reviewed version

Link back to DTU Orbit

Citation (APA):

Ekhtiari, M., Zhang, Z., \& Andersen, M. A. E. (2016). Analysis of bi-directional piezoelectric-based converters for zero-voltage switching operation. IEEE Transactions on Power Electronics, 32(1), [7425240].

https://doi.org/10.1109/TPEL.2016.2537820

\section{General rights}

Copyright and moral rights for the publications made accessible in the public portal are retained by the authors and/or other copyright owners and it is a condition of accessing publications that users recognise and abide by the legal requirements associated with these rights.

- Users may download and print one copy of any publication from the public portal for the purpose of private study or research.

- You may not further distribute the material or use it for any profit-making activity or commercial gain

- You may freely distribute the URL identifying the publication in the public portal

If you believe that this document breaches copyright please contact us providing details, and we will remove access to the work immediately and investigate your claim. 


\title{
Analysis of bi-directional piezoelectric-based converters for zero-voltage switching operation
}

\author{
Marzieh Ekhtiari, Student Member, IEEE, Zhe Zhang Member, IEEE, and \\ Michael A. E. Andersen, Member, IEEE
}

\begin{abstract}
This paper deals with a thorough analysis of zerovoltage switching especially for bi-directional, inductorless, piezoelectric transformer-based switch-mode power supplies with a half-bridge topology. Practically, obtaining zero-voltage switching for all of the switches in a bi-directional piezoelectric power converter is a difficult task. However, the analysis in this work will be convenient for overcoming this challenge. The analysis defines the zero-voltage region indicating the operating points whether or not soft switching can be met over the switching frequency and load range. For the first time, a comprehensive analysis is provided, which can be used as a design guideline for applying control techniques in order to drive switches in piezoelectric transformer-based converters. This study further conveys the proposed method to the region where all the switches can obtain soft switching. Moreover, the analysis can be applied to other types of resonant converters with or without piezoelectric transformers. Experimental and simulation results are provided, verifying the performed analysis.
\end{abstract}

Index Terms-Resonant converter; zero-voltage switching; piezoelectric transformer; optimum dead time; phase shift control.

\section{NOMENCLATURE}

$v_{F P} \quad$ Switching voltage in the primary side of the transformer.

$v_{F S} \quad$ Switching voltage in the secondary side of the transformer.

$i_{\text {res }} \quad$ Resonant current of the piezoelectric transformer.

$\Phi_{I} \quad$ Phase shift of the resonant current with reference to the turn-off time of the low-side switch.

$\Phi_{O D T, P}$ Phase corresponding to the optimum dead time in the primary-side switching.

$\Phi_{O D T, S}$ Phase corresponding to the optimum dead time in the secondary-side switching.

$C_{d 1} \quad$ Input electrode capacitance of the piezoelectric transformer.

$C_{d 2} \quad$ Output electrode capacitance of the piezoelectric transformer.

$C_{\text {oss }} \quad$ Output capacitance of MOSFETs or parasitic capacitance of rectifier's diodes.

$C_{i n} \quad$ Equivalent input capacitance of the piezoelectric transformer and switches.

$C_{\text {out }} \quad$ Equivalent output capacitance of the piezoelectric transformer and switches.

NELIP Normalized effective load impedance plane.

$Z_{p} \quad$ Impedance seen from the inverter's switching node.

All authors are with the Electronics Group, Department of Electrical Engineering, Technical University of Denmark, Richard Petersens Plads, bldg. 325, Kgs. Lyngby, DK-2800, Denmark.

E-mail: maekh@elektro.dtu.dk,zz@elektro.dtu.dk,ma@elektro.dtu.dk.
$Z_{s} \quad$ Impedance seen from the rectifier's switching node.

$Z_{n p} \quad$ Effective impedance seen from the inverter's switching node.

$R_{n p} \quad$ Normalized effective real part of $Z_{n p}$.

$X_{n p} \quad$ Normalized effective reactance of $Z_{n p}$.

$Z_{n s} \quad$ Effective impedance seen from the rectifier's switching node.

$R_{n s} \quad$ Normalized effective real part of $Z_{n s}$.

$X_{n s} \quad$ Normalized effective reactance of $Z_{n s}$.

\section{INTRODUCTION}

Piezoelectric ceramic transformers (PTs) allow the replacement of magnetic transformers with a single ceramic component [1]. In some specific applications, e.g. with low cost, low size, low electromagnetic interference (EMI), PTs are preferred over electromagnetic transformers [2], [3]. PTs are initially considered as high-voltage transformer devices [2], [4]. This has rapidly increased the research and development within PT-based power converters [5]-[8] due to their high power density and high efficiency. Recently, inductorless PTbased switch-mode power supplies (SMPS) are used because of their specific usage in nonmagnetic applications [9]-[12]. The elimination of a bulky inductor reduces the size, weight, EMI, and cost [13].

A PT behaves as a resonant LC tank in its resonance frequency [13]. Therefore, PTs are employed to entirely replace the resonant network in resonant power converters. A resonant converter is simply composed of a switching network (i.e. an inverter), a resonant network, a rectifier network and a load. The block diagram of this system is shown in Fig. 1. The switching network can be either half-bridge or full-bridge configuration. The resonant network is classified as resonant tank or PT. A variety of resonant tanks can be employed i.e. a series resonant tank comprised of series LC, parallel resonant tank comprised of parallel LC tank, LLC or LCC tank networks [14]-[17]. The rectifier network is either passive [15], [18] or active, comprised of a diode rectifier network or switching network. In order to increase the converter's efficiency, it is particularly important to operate the converter in the desired operating points, where zerovoltage switching (ZVS) is ensured. However, the conditions for achieving ZVS varies with temperature, the load and the switching frequency [5], [19], [20]. Therefore, it is desirable to find the frequency range and the load variations in which ZVS can still be obtained [21]. However, PT-based resonant converters are typically operated with a switching frequency to have an inductive impedance seen from switching node 


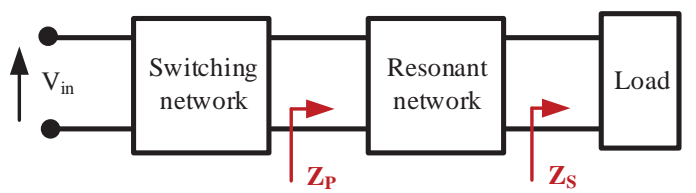

Fig. 1: A simple block diagram of a resonant converter.

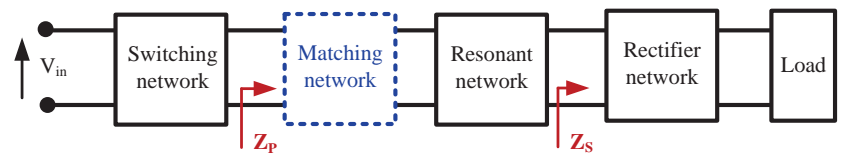

Fig. 2: A simple block diagram of a resonant converter.

$\left(Z_{P}\right)$ [12], [22], [23], but this does not ensure the achievement of ZVS [24]. Furtheremore, characteristics of the PT should allow for obtaining soft switching [5], [22]. Several attempts have been made to express the soft switching capability especially for PTs with some limitations [5], [25].

The commonly used solution is to add a matching network between the switching network and the resonant network, as shown in Fig. 2. The load-source matching networks can be designed to shift the operating point to the area where $\mathrm{ZVS}$ is attained. In the most cases this is done by utilizing an additional series inductor between the switching network and the resonant network [4], [26]. Moreover, the matching network usually consists of an inductor, which is not a suitable solution for the inductorless converter topologies, due to its nonmagnetic applications [9]. This thereby brings some limitations to utilizing the solution of matching network.

Another solution within the PT-based SMPS is to have a PT which is inherently capable of obtaining soft switching. This requires several conditions to be fulfilled in the design of the PT [5] for a certain load. There is a narrow frequency band within which the PT shows an inductive characteristic [27]. Therefore, achieving ZVS for the PT-based driver under various range of loads is quite challenging [9], [22], [23], [26].

To date there are literatures about ZVS, but not specifically for power converters with piezoelectric transformers. However, existing solutions can be utilized for PT-based converters in a limited operating conditions. The analysis in this paper, extends the ZVS region and conditions for attaining ZVS to a broader range. The goal of this paper is to investigate the PTbased converter's operating points to meet soft switching both for the inverter and the rectifier networks. The investigation performed in this paper can be generalized for all types of resonant converters, even though the discussion focuses on PT-based converters. The main purpose is to find a simplified equivalent impedance seen from the switching node to find the ZVS region. Ultimately, the method represented in this paper can help overcome the limitations in control technology of PT-based drivers [28]. Furthermore, this work gives an estimation on the value of the minimum required dead time (DT) under the soft switching condition. Obtaining the minimum or optimum DT results in an efficiency increase of the converter. The proposed converter can be used for energy recovery from the capacitive loads, e.g. piezo actuators (PA) in [9] and [26], Dielectric electro active polymers (DEAP) actuators in [28]. Moreover, the application of this paper is not limited to the PT-based converters. It can be applied for other type of resonant converters as are named in this Section. Implementation of energy recovery strategies will be the key to obtain a highly efficient converter system which imposes strict requirements on advanced control schemes. This work help on understanding the concept through analysis in order to imply advanced control strategy for different applications.

The paper is organized as follows. Section II deals with the half-bridge rectifier network. Subsection II-A is dedicated to a description of a bi-directional converter's topology and related waveforms for a general case. The description is followed by analysis of active rectifier network in Subsection II-B. Section III describes a zero-voltage switching region specifically for the inverter network. Furthermore, analysis of waveforms is performed for the primary-side switches in Subsection III-A and for defining the ZVS-boundary in Subsection III-B. This analysis generally leads to the ZVS region and the optimum DT for the PT-based converters. Following this, analysis of the ZVS region is carried out in Section IV for the rectifier network. The description is followed by analysis for a passive rectifier network in Subsection IV-B and its boundary in Subsection IV-A. A short discussion follows in Subsection IV-D about the equivalent resistor of the output network for the resonant converters with series resonant tank. Experimental and simulation results are provided in Subsections III-C and IV-C.

\section{PT-BASED SMPS WITH HALF-BRIDGE RECTIFIER NETWORK}

The half-bridge PT-based SMPS operates similar to the true Class DE inverter studied in [29]. In addition to previous research, this paper investigates the large-scope operation of waveforms and ZVS region for the uni-directional and bidirectional topologies. The analytical method was inspired from the principle of equivalent impedances $Z_{P}$ and $Z_{S}$ through Fourier analysis [30], employed to determine the ZVS region. The $Z_{P}$ is seen from the switching network and $Z_{S}$ is seen from input of the active rectifier network. In the PT-based SMPS, the input capacitance and the output capacitance of the PT, in parallel with the output capacitances of the switches, should be fully charged and discharged for attaining ZVS. Since the input and output capacitance of PTs are typically larger than the output capacitances of metal-oxide-semiconductor field-effect transistors (MOSFETs), achieving ZVS is more challenging in these kinds of converters compared to class DE converters. Presently, bi-directional topology is not commonly used in PTbased converters. Therefore, the purpose of this work is to give a comprehensive analysis for the bi-directional functionality of PT-based SMPS.

\section{A. Bi-directional topology}

Bi-directional PT-based SMPS with the active half-bridge rectifier shown in Fig. 3 and is studied in this work. Fig. 4 shows bi-directional prototype built and used for experimental results in this work. The following analysis focuses on finding equivalent impedances $Z_{P}$ and $Z_{S}$ shown in Fig. 3. The resonant current is dependent on the resonant components in 


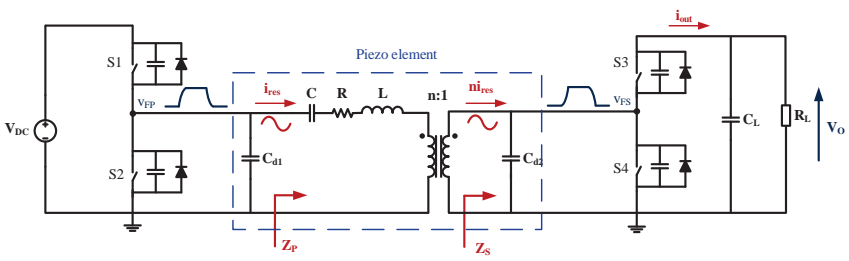

Fig. 3: Bi-directional PT-based switch-mode power supply.The Mason's lumped parameter model is used for PT [31]-[33].

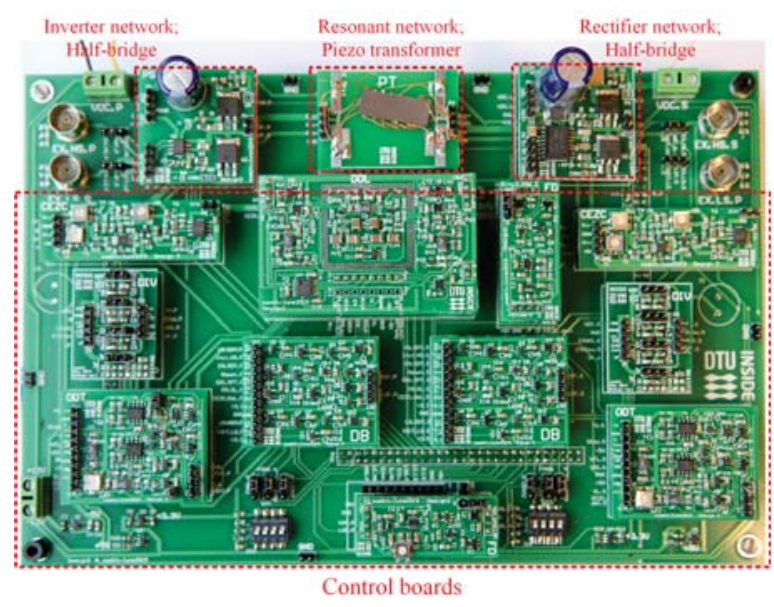

Fig. 4: The prototype of bi-directional PT-based switch-mode power supply.

the resonant network as well as the load. The impedance $Z_{S}$ is the equivalent impedance of the rectifier network together with the load. Therefore, $Z_{S}$ is also load dependent. In other words, changes in the load, make changes in the impedance seen from the output of the PT. This causes changes in the phase and the amplitude of the resonant current. Consequently, changes in the load convert to the equivalent impedance seen from the switching node, $Z_{P}$. Principally, the impedance $Z_{P}$, which is calculated in Section III, is dependent on the load, the switching frequency, and the phase shift between the resonant current and the fundamental component of the switching voltage. This then helps us to find the ZVS region for the switching network. For simplicity, the following analysis is based on the following assumptions that do not affect the general aspect of the results:

- The converter's input capacitor is considered as a summation of the PT's input capacitance and both MOSFET's output capacitances in the switching network:

$$
C_{i n}=C_{d 1}+2 C_{o s s}
$$

- The converter's output capacitor is considered as a summation of the PT's output capacitance and both MOSFET's output capacitances in the rectifier network:

$$
C_{\text {out }}=C_{d 2}+2 C_{\text {oss }}
$$

- The load capacitor is large enough to keep the output voltage in a constant level without any ripple.

- The temperature of the PT remains constant.
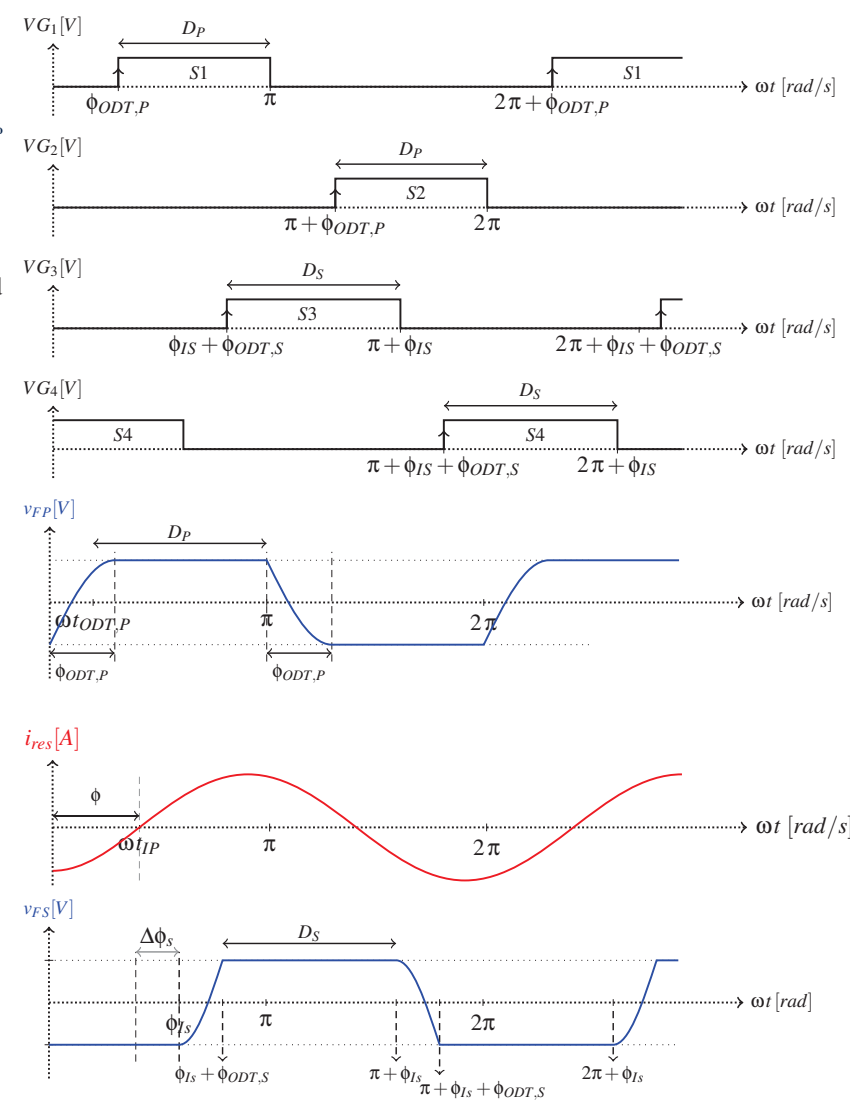

Fig. 5: Waveforms in the bi-directional topology: Gate voltage of switches, resonant current $i_{\text {res }}$ and switching voltages of the inverter $v_{F P}$ and the rectifier $v_{F S}$.

Fig. 5 shows overall waveforms for the inductorless PTbased SMPS. Utilizing an active rectifier allows for having an active phase shift between the rectifier switches and the inverter switches that consequently enables a bi-directional power flow [23]. In order to have full control of the power flow in the bi-directional mode, the key is to control the phase shift between the two switching networks, $\phi+\Delta \phi_{s}$. Moreover, the target is to have ZVS for the switches on both primaryand secondary-sides of the PT to improve the efficiency. In order to achieve ZVS, the gate voltages of the switches should allow for the voltage $v_{F P}$ to lead the resonant current and the voltage $v_{F S}$ to lag the resonant current. Applying an amount of the phase shift, $\Delta \phi_{s}$, allows for changes in the power flow and ultimately changes the level of the output voltage. This change further causes changes in the amplitude and the phase shift of the resonant current, $\phi$. Consequently, this affects the time span where the switching voltage transits between the rails, which is called minimum or optimum DT under the ZVS condition. Moreover, it is important to investigate the operating points that rectifier network or the inverter network can achieve ZVS for each output voltage level. Accordingly, this work analyzes the comprehensive situation for variations of $\Delta \phi_{s}$ versus $\phi$ and suggests the optimum DT for obtaining ZVS. 


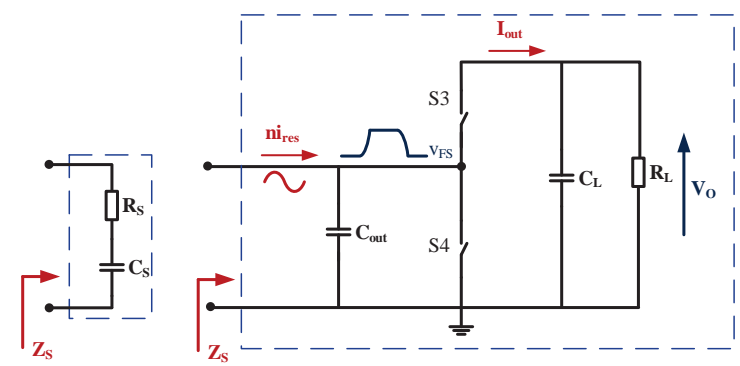

(a) Electrical equivalent circuit.
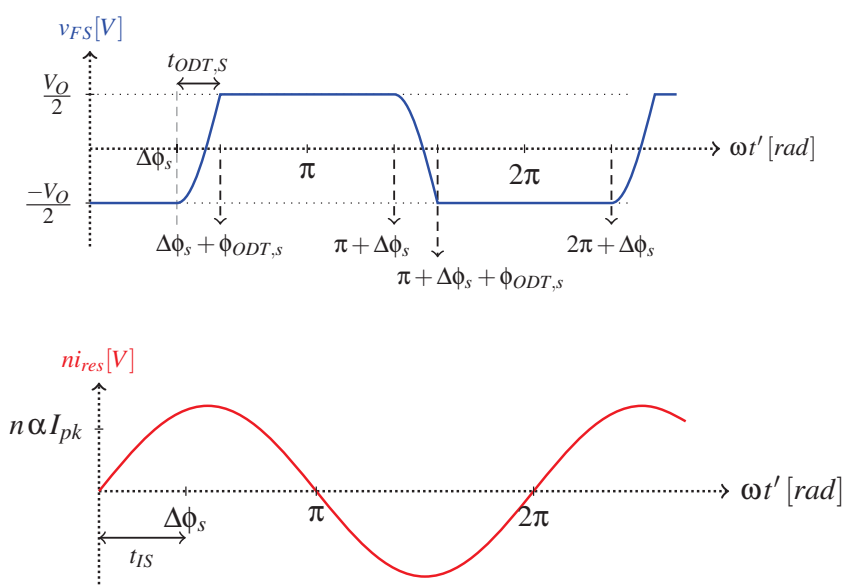

(b) Signal waveforms.

Fig. 6: Output circuit of the converter with active rectifier. Waveforms: resonant current $i_{\text {res }}$ and floating voltage $v_{F S}$ in the general state.

\section{B. The converter's output characteristic}

In the following analysis, for simplicity, the normalized time axis is changed to $\omega t^{\prime}$ where $\omega t^{\prime}=\omega t-\phi$. Thereby, the resonant current is considered with zero phase shift. There is a phase shift between the current and the time where the low-side switch is turned off, which is defined as $\Delta \phi_{S}$.

$$
i_{\text {res }}\left(t^{\prime}\right)=I_{p k} \sin \left(\omega t^{\prime}\right)
$$

The output voltage is found as:

$$
V_{o}=\frac{2 n R_{L} I_{p k} \cos \left(\Delta \phi_{s}\right)}{2 \pi+R_{L n}}
$$

where, $R_{L n}=\omega R_{L} C_{\text {out }}$ is a normalized load resistance. Hence, the output power will be

$$
P_{\text {out }}=\frac{4}{R_{L}}\left(\frac{n I_{p k} \cos \left(\Delta \phi_{S}\right)}{2 \pi+R_{L n}}\right)^{2}
$$

The normalized impedances seen from the rectifier's floating point is $Z_{n s}=R_{n s}+j X_{n s}$, where the effective real part is

$$
R_{n s}=\frac{8 R_{L n} \cos ^{2}\left(\Delta \phi_{s}\right)}{\left(2 \pi+R_{L n}\right)^{2}}
$$

and the effective reactance is described as

$$
X_{n s}=\frac{A}{\pi} \frac{2 \pi-R_{L n}}{\left(2 \pi+R_{L n}\right)^{2}} \cos \left(\Delta \phi_{S}\right)-\frac{1}{\pi}\left(\phi_{O D T, S}+\sin \left(2 \Delta \phi_{S}\right)\right)
$$

from Equation (4), $\Delta \phi_{s}$ can be derived as a factor of other parameters.

$$
\Delta \phi_{s}=\cos ^{-1}\left(\frac{V_{o}}{2 n R_{L} I_{p k}}\left(2 \pi+R_{L n}\right)\right)
$$

Equation (8) gives a relationship to calculate the required phase shift of the rectifier switches, $\Delta \phi_{s}$, for the voltage level of $V_{o}$ over the switching frequency of $\omega$ and load of $R_{L}$. The following equations will be further discussed in Section IV regarding the ZVS region for the rectifier. More details about finding $R_{n s}$ and $X_{n s}$ are described in the appendix.

\section{ZVS FOR THE INVERTER NETWORK}

\section{A. Analysis of impedance $Z_{P}$}

Fig. 7 shows the input circuit of the converter and the related waveforms; the floating voltage $v_{F P}$ and the resonant current $\left(i_{\text {res }}\right)$, which are studied in detail in the following analysis. Since piezo transformers have a high quality factor [34], higher harmonics are filtered out and only the fundamental component of the current passes through the output [27], [35]. Therefore, the resonant current is a sinusoidal waveform with a peak amplitude of $I_{p k}$ and a phase shift of $\phi$.

$$
i_{\text {res }}(t)=I_{p k} \sin (\omega t-\phi)
$$

where, $\phi$ is phase shift between resonant current and the turnoff time of the low-side switch, $S 2$, described by Equation (10). At the time point $t_{O D T, P}$, the floating voltage $v_{F P}$ transits between voltage rails. The resonant current changes its direction when the high-side switch conducts; either S1 is turned on or its body diodes clamps. Therefore, $\phi \geqq \phi_{O D T, P}$.

$$
\begin{array}{cl}
\phi=\omega t_{I P} & \phi \in[0, \pi] \\
\phi_{O D T, P}=\omega t_{O D T, P} & \phi_{O D T, P} \in[0, \pi] \quad \text { and } \phi_{O D T, P} \leqslant \phi
\end{array}
$$

For convenience, the dc input is shown as a center-taped supply. This eases finding the Fourier components by applying symmetry to the waveforms. When the low-side switch is turned off at $t=0$, both switches $S 2$ and $S 1$ are off. The resonant current keeps its direction in the reverse orientation charging the input capacitance $C_{i n}$ to the positive rail. The optimum DT, $t_{O D T}$, is defined as the time when the voltage across $C_{i n}, v_{F P}$, reaches to $V_{D C} / 2$. At this time point, the highside switch $S 1$ is turned on before its body diode starts to conduct. This further prevents unnecessary dead time between the switches and consequently, efficiency increment. Normalized input impedance seen from the inverter's floating point is found as $Z_{n p}=R_{n p}+j X_{n p}$, where the effective real part and the effective reactance is described as (12) and (13)

$$
\begin{aligned}
R_{n p} & =\frac{-1}{\pi}\left[\frac{-1}{2} \sin \left(2 \phi_{O D T, P}-\phi\right) \sin (\phi)-\frac{1}{2} \sin ^{2}(\phi)\right. \\
& +\phi_{O D T, P} \sin (\phi) \cos \left(\phi_{O D T, P}\right)-\phi_{O D T, P} \cos (\phi) \sin \left(\phi_{O D T, P}\right) \\
& \left.-\frac{1}{2} \cos \left(2 \phi_{O D T, P}-\phi\right) \cos (\phi)+\frac{1}{2} \cos ^{2}(\phi)\right]
\end{aligned}
$$


and consequently $\phi=\phi_{O D T . P}$. Substituting $\phi_{O D T . P}=\phi$ into Equations (12) and (13) results in the following equations.

$$
\begin{gathered}
R_{n P, B}=\frac{1}{\pi}\left[\sin ^{2}(\phi)\right] \\
X_{n P, B}=\frac{-1}{\pi}[-\phi+\sin (\phi) \cos (\phi)]
\end{gathered}
$$

The duty cycle of the switches in this case is:

$$
D_{P, B}=\frac{\pi-\phi}{2 \pi}
$$

(a) Electrical equivalent circuit.
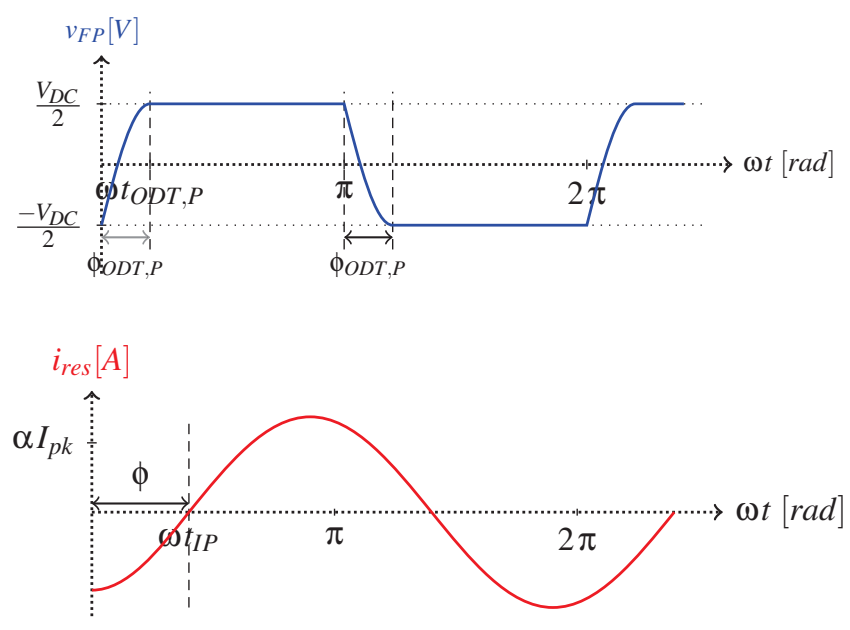

(b) Signal waveforms $i_{\text {res }}$ and $v_{F P}$.

Fig. 7: Primary-side of the SMPS considering general operation where the resonant current and the input floating voltage have phase shift of $\phi$.

$$
\begin{aligned}
X_{n p} & =\frac{-1}{\pi}\left[-\phi_{O D T, P} \sin \left(\phi_{O D T, P}\right) \sin (\phi)\right. \\
& -\frac{1}{2} \cos \left(2 \phi_{O D T, P}-\phi\right) \sin (\phi)+\frac{1}{2} \cos (\phi) \sin (\phi) \\
& +\frac{1}{2} \cos (\phi) \sin \left(2 \phi_{O D T, P}-\phi\right)+\frac{1}{2} \sin (\phi) \cos (\phi) \\
& \left.-\phi_{O D T, P} \cos (\phi) \cos \left(\phi_{O D T, P}\right)\right]
\end{aligned}
$$

The inverter's switches operate with a duty cycle of $D_{P} \in$ $[0,0.5]$;

$$
D_{P}=\frac{\pi-\phi_{O D T, P}}{2 \pi}
$$

Details for finding $Z_{n p}$ are described in the appendix.

\section{B. ZVS region boundary for the inverter}

The resonant current has a phase shift with the floating voltage, which varies with the parameters of the piezo transformer and the load. For operating points located on the boundary of ZVS region, the resonant current crosses zero when the $v_{F P}$ reaches the rails at its peak value. This means that the voltage across the input capacitor $C_{i n}$ reaches its peak value at the optimum dead time. Therefore, $d v_{F P} / d t=0$ at $t_{O D T, P}$. This occurs when the resonant current crosses zero
The complex impedance plane of $Z_{n p}$ which is the $R_{n p}-X_{n p}$ plane named as the normalized effective load impedance plane (NELIP) in Fig. 8. The Locus of ZVS is shown in the NELIP. The boundary of the ZVS region shows the case where the voltage across $C_{i n}$ reaches the positive rail at its peak value. The boundary of ZVS region in the NELIP plane is designated by the operating points $R_{n P, B}$ and $X_{n P, B}$ which are shown by a cycloid defined as:

$$
X_{n P, B}=r \cos ^{-1}\left(1-\frac{R_{n P, B}}{r}\right)-\sqrt{R_{n P, B}\left(2 r-R_{n P, B}\right)}
$$

This cycloid is the locus of a point on the rim of a circle of radius $r$ rolling along the $X_{n p}$ axis, where $r=1 / 2 \pi$. The arch of cycloid is shown in Fig. 8 which is closed by a line across $X_{n p}$. In this case, the amplitude of the resonant current is:

$$
I_{p k, B}=\frac{V_{D C} \omega C_{i n}}{1-\cos (\phi)}
$$

Therefore, $I_{p k}$ for any case can be defined as a multiple factor of $I_{p k, B}$ by the factor of $\alpha$.

$$
I_{p k}=\alpha I_{p k, B}
$$

The equivalent impedance, $Z_{p e}$, of the converter seen from the switching node of the inverter is dependent on the load, output voltage and the duty cycle of the rectifier. The ZVS region is found by comparing this equivalent impedance in all cases to the critical case located on the cycloid. Therefore, two cases where $Z_{p e}$ is located inside and outside of the NELIP plane are described as follows:

- Inside the ZVS region: In the case that $Z_{p e}$ has small values, $\alpha$ will be greater than $1, \alpha>1$, and $I_{p k} \geq I_{p k, B}$. In this situation the effective impedance is located inside the ZVS region, shown as the filled gray area in Fig. 8 bounded by the cycloid and the $X_{n p}$ axis. Therefore, the switching voltage $v_{F P}$ reaches the rails before the zero crossing of the resonant current, and consequently, $\phi_{O D T, P}<\phi$. Hence, the duty factor of the switches, $D_{P}$, can be increased by detecting the optimum DT which means turning on the switches $S 2$ and $S 1$ at $t_{O D T, P}$ and $T / 2+t_{O D T, P}$, respectively. Therefore, the converter's efficiency increases due to ZVS operation. For resonant converters there is access to measure the amplitude and phase of the resonant current and thereby, the optimum DT is found as:

$$
\phi_{O D T, P}=\phi-\cos ^{-1}\left(\frac{1+(\alpha-1) \cos (\phi)}{\alpha}\right)
$$

In the PT-based converters typically there is no access 


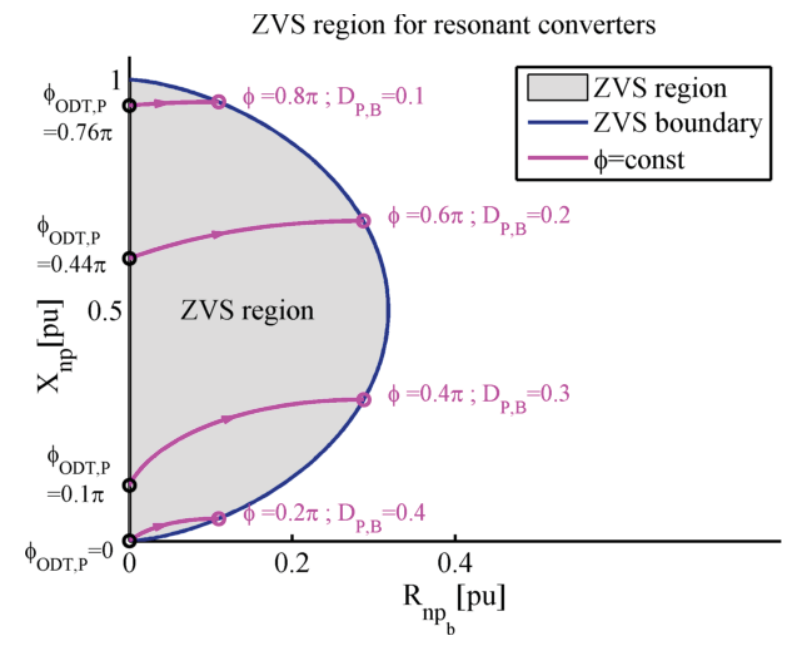

Fig. 8: Zero-voltage switching region.

to the resonant current inside the transformer package. Therefore, application of this equation is limited in practice for PT-based converters.

- Outside the ZVS region: This is the region of operating points for which the effective impedance is located outside the gray area. This occurs when $Z_{p e}$ has large values and $\alpha<1$. This means that the amplitude of the resonant current is not large enough to charge the input capacitance of the PT, $C_{i n}$, to the positive rail. Therefore, zero voltage switching cannot be attained.

\section{Inverter's results}

Fig. 8 shows mapping of the NELIP plane. Additionally, the curves show maps of points inside the ZVS region from the equations in Section III. Points marked from each curve and located on the boundary of ZVS region can also be found by substituting $\phi_{O D T}=\phi$ in the equations provided in Subsection III-A. For instance if $\phi=0.6 \pi$, the $\phi_{O D T, P}$ can vary from $0.44 \pi$ to $0.6 \pi$ depending on the amplitude of the resonant current. In the case of resonant converters with discrete resonant tanks such as LC, LLC and LCC, there is access to measure the amplitude and phase of the resonant current. Therefore, the phase of the optimum dead time, $\phi_{O D T, P}$, is found from the related equations, and it corresponds to one of the points inside the NELIP. However, there is no access to sense the amplitude and phase of the resonant current inside the piezo transformers, but the analysis can be used to estimate the range of the optimum DT. Simulation results are shown in Fig. 9 for the half-bridge diode rectifier PT-based converter. These results show how the frequency, the phase shift of the resonant current and the optimum DT change when the voltage gain varies where ZVS is obtained. Furthermore, all the points are mapped in the NELIP plane. They are well situated inside the ZVS region by substituting in Equations (12) and (13). Fig. 10 shows experimental results for two operating points in the PT-base SMPS. Fig. 10a shows $v_{F P}$ when the load of the PT is resistive. This operating point is mapped in $P_{1}$ in the NELIP plane in Fig. 10c. Fig. 10b shows $v_{F P}$ when the load
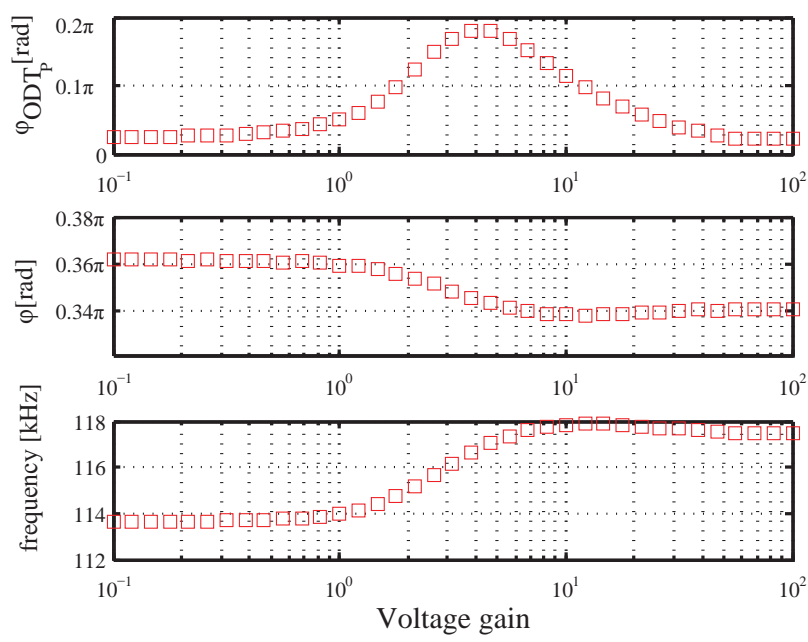

(a) Simulation data points, $V_{\text {in }}=10 \mathrm{~V}$.

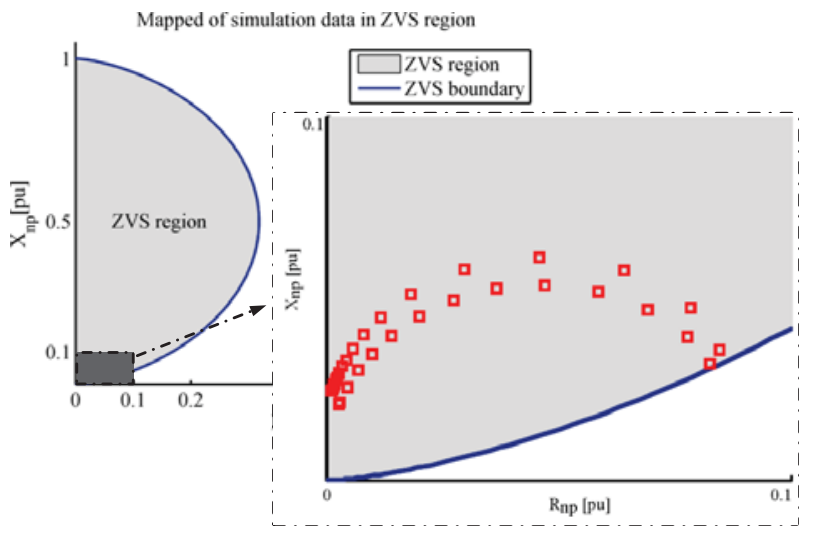

(b) Mapped of operating points in the inverter's NELIP.

Fig. 9: Simulation data of PT-based converter with a diode rectifier.

of the PT is passive rectifier. This operating point is mapped in $P_{2}$ in the NELIP plane (Fig. 10c.). In both cases a large DT is chosen in order to see the local peak of the voltage. As previously mentioned, the voltage $v_{F P}$ passes through its peak when the resonant current crosses zero. Therefore, the phase of the resonant current, $\phi$, is measured. The phase corresponding to the time that $v_{F P}$ reaches the positive rail is measured as $\phi_{O D T, P} . P_{1}$ and $P_{2}$ are mapped by substituting the measured values into Equations (12) and (13). Experimental waveforms show that ZVS is attained and in the NELIP plane $P_{1}$ and $P_{2}$ are also located inside the ZVS region. The measured values are shown in Table I. For $P_{2}$ the measured value for $\phi_{O D T, P}$ is $0.54 \pi$, which is in the range of $[0.35 \pi, 0.55 \pi]$ shown by the curve for possible operating points positioned on the curve, where the phase of the resonant current is $\phi=0.55 \pi$. Furthremore, the points $P_{1, B}$ and $P_{2, B}$ located on the boundary of NELIP plane show the case explained in Subsection III-B. 


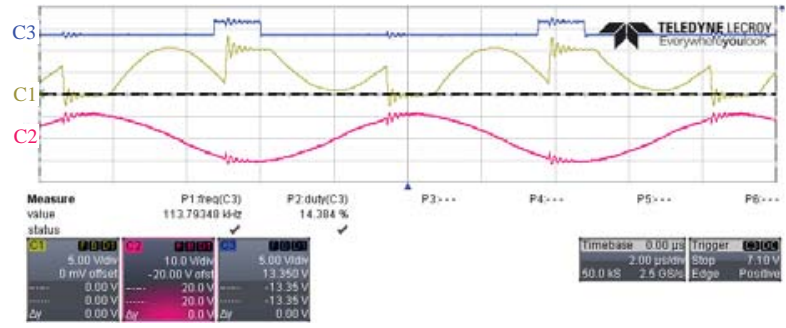

(a) An operating point (P1) for the PT-based converter with resistive load with $V_{\text {in }}=10 \mathrm{~V}$, frequency $=113.8 \mathrm{kHz}, R_{L}=775 \Omega$. C1: Inverter's switching voltage $v_{F P}$; C2: Output voltage of the converter with resistive load; C3: Gate voltage of the S1.

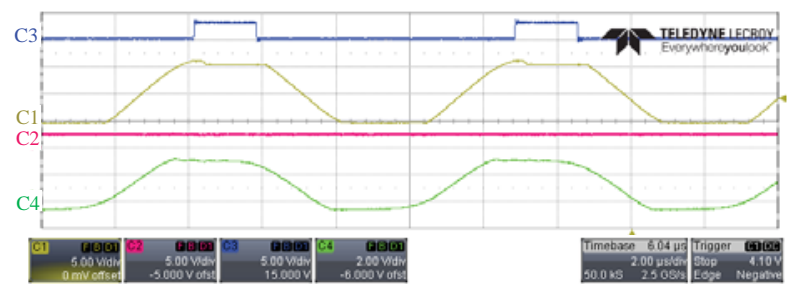

(b) An operating point (P2) for the PT-based converter with half-bridge diode rectifier with $V_{i n}=10 \mathrm{~V}$, frequency $=114.8 \mathrm{kHz}, R_{L}=100 \Omega, V_{o}=2.5 \mathrm{~V}$. C1: Inverter's switching voltage $v_{F P} ; \mathrm{C} 2$ : Output voltage $V_{o} ; \mathrm{C} 3$ : Gate voltage of the S1; C4: Rectifier's switching voltage $v_{F S}$.

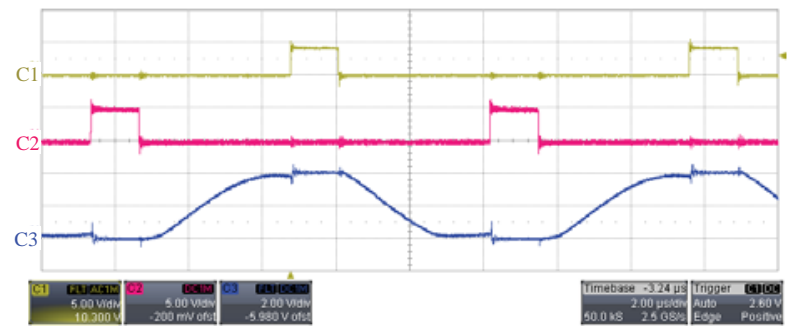

(c) An operating point $\left(P_{1, B}\right)$ located in the boundary of NELIP plane with $V_{i n}=4 \mathrm{~V}$, frequency $=106 \mathrm{kHz}, V_{o}=5 \mathrm{~V}$. C1: Gate voltage of the S1; C2: Gate voltage of the S2; C3:Inverter's switching voltage $v_{F P}$.

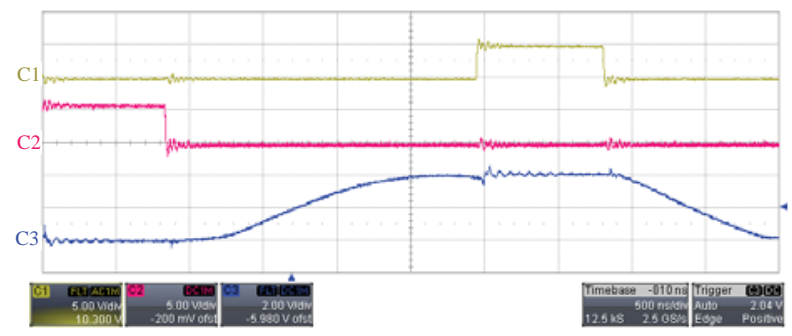

(d) An operating point $\left(P_{2, B}\right)$ located in the boundary of NELIP plane with $V_{\text {in }}=4 \mathrm{~V}$, frequency $=169 \mathrm{kHz}, V_{o}=5 \mathrm{~V}$. C1: Gate voltage of the $\mathrm{S} 1 ; \mathrm{C} 2$ : Gate voltage of the S2; C3:Inverter's switching voltage $v_{F P}$.

TABLE I: Measuring the resonant current's phase $\phi$, and $\phi_{O D T, P}$.

\begin{tabular}{ccc}
\hline \hline Point & $\phi(\mathrm{rad})$ & $\phi_{O D T, P}(\mathrm{rad})$ \\
\hline$P_{1}$ & $0.37 \pi$ & $0.26 \pi$ \\
$P_{2}$ & $0.54 \pi$ & $0.37 \pi$ \\
\hline \hline
\end{tabular}

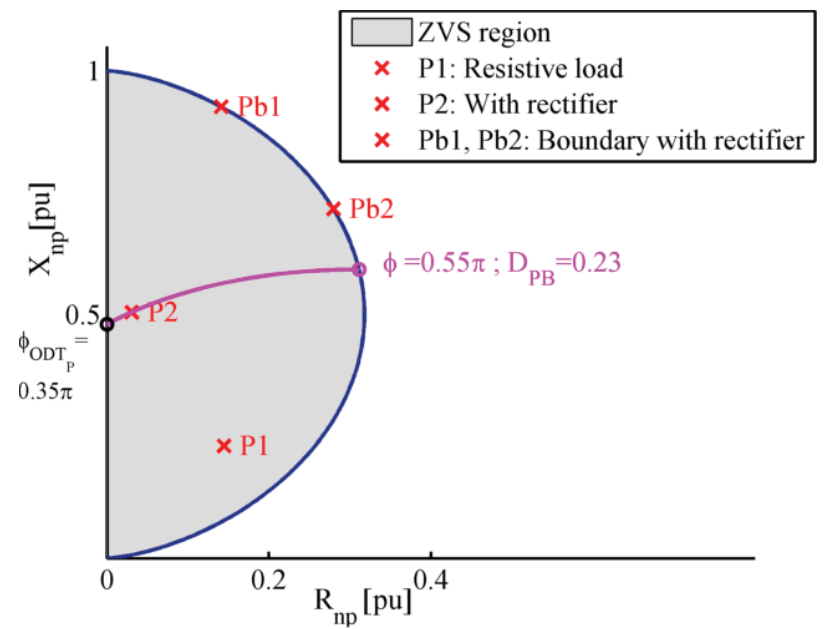

(e) Map of operating points in the inverter's NELIP.

Fig. 10: Experimental results.

\section{ZVS REGION FOR THE RECTIFIER NETWORK}

\section{A. ZVS boundary of active rectifier network}

In critical points located on the boundary of the ZVS region, the resonant current crosses zero precisely when the voltage across $C_{\text {out }}$ reaches its peak value at the end of DT. This further means $\Delta \phi_{s}=0$ or $\phi_{I S}=\phi$ in waveforms shown in Fig. 5, where generally the relationship between the phases is $\phi_{I S}=\phi+\Delta \phi_{S}$. Substituting $\Delta \phi_{s}=0$ into Equations (6-8) results in:

$$
R_{n s}=\frac{8 R_{L n}}{\left(2 \pi+R_{L n}\right)^{2}}
$$

and the effective reactance is described as

$$
X_{n s}=\sqrt{\frac{8 R_{L n}}{\pi}} \frac{2 \pi-R_{L n}}{\left(2 \pi+R_{L n}\right)^{2}}-\frac{1}{\pi} \phi_{O D T, S}
$$

where

$$
\phi_{O D T, S}=\cos ^{-1}\left(\frac{2 \pi-R_{L n}}{2 \pi+R_{L n}}\right)
$$

If $C_{\text {out }}=2 C_{d}$ the results are in good agreement with previous research [36].

\section{B. Diode rectifier network}

The analysis for passive rectifier network is the same as in Subsection IV-A, after substituting $\Delta \phi_{S}=0$. When the resonant current passes through zero from negative direction to the positive direction, it starts to charge the output capacitance until the voltage across $C_{\text {out }}$ reaches a voltage slightly higher than the output voltage to the value of $V_{d}$, which causes the high-side diode to start to conduct. Then, the switching voltage $v_{F S}$ is clamped to the positive rail voltage until the resonant current changes direction from the positive to negative. Therefore, the output capacitance starts to discharge until the $v_{F S}$ reaches the negative rail. In this situation, the resonant current does not necessarily crosses zero at the end of DT, which makes it different to the case described in Subsection IV-A. Furthermore, the voltage drop across the diodes affects the 


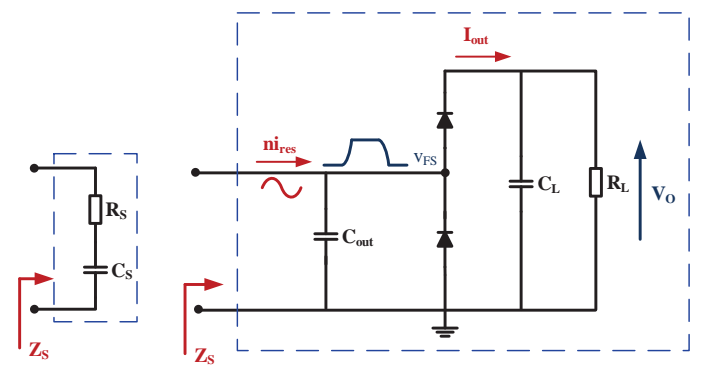

(a) Elecreical equivalent circuit.
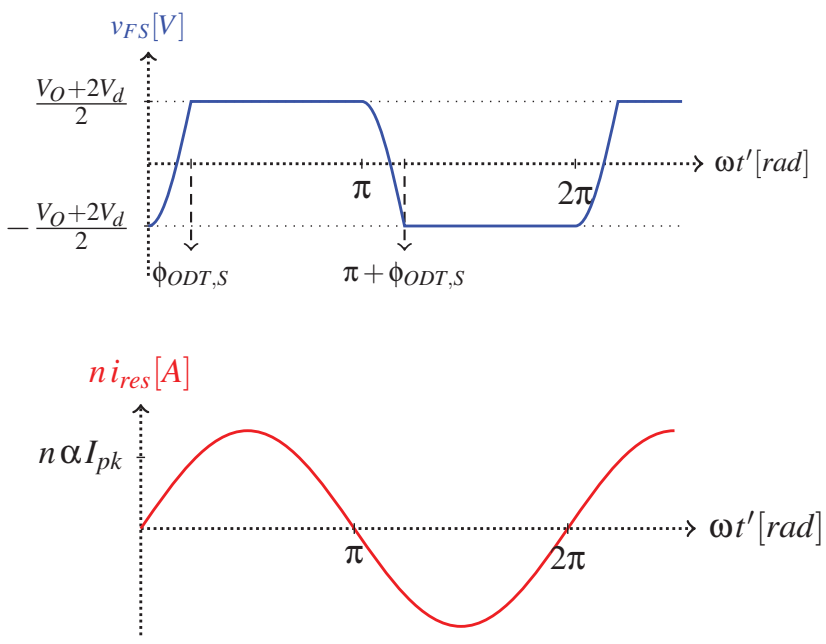

(b) Signal waveforms $i_{\text {res }}$ and $v_{F P}$.

Fig. 11: Half-bridge rectifier in the secondary side of the piezo transformer, forward voltage conduction of the diode $V_{d}$ are considered. Passive rectifier network and signal waveforms for diodes $\Delta \phi_{s}=0$ are shown.

impedance seen from the input of the rectifier. While the rectifiers are conducting, the output voltage of the PT is clamped to the output voltage, which is considered as a DC voltage $V_{o}$. Thereby, the output current goes through the load resistance.

$$
V_{o}=R_{L}<I_{\text {out }}>=\frac{2 n R_{L} I_{p k}}{2 \pi+R_{L n}^{\prime}}
$$

where $R_{L n}^{\prime}=R_{L n}\left(1+2 V_{d f}\right)$ and $V_{d f}=\frac{V_{d}}{V_{o}}$, which results in

$$
P_{\text {out }}=V_{o}<I_{\text {out }}>=\frac{4}{R_{L}}\left(\frac{n I_{p k}}{2 \pi+R_{L n}^{\prime}}\right)^{2}
$$

The effective impedance $Z_{n s}$ is found by the same equations as in Section IV-A, where the normalized load resistance will be $R_{L n}^{\prime}$ by considering the forward voltages of the diodes.

$$
R_{n s}=\frac{8 R_{L n}^{\prime}}{\left(2 \pi+R_{L n}^{\prime}\right)^{2}}
$$

and

$$
\begin{gathered}
X_{n s}=\sqrt{\frac{8 R_{L n}^{\prime}}{\pi}} \frac{2 \pi-R_{L n}^{\prime}}{\left(2 \pi+R_{L n}^{\prime}\right)^{2}}-\frac{\phi_{O D T, S}}{\pi} \\
\phi_{O D T, S}=\cos ^{-1}\left(\frac{2 \pi-R_{L n}^{\prime}}{2 \pi+R_{L n}^{\prime}}\right)
\end{gathered}
$$

These equations are in agreement with previous research [18].

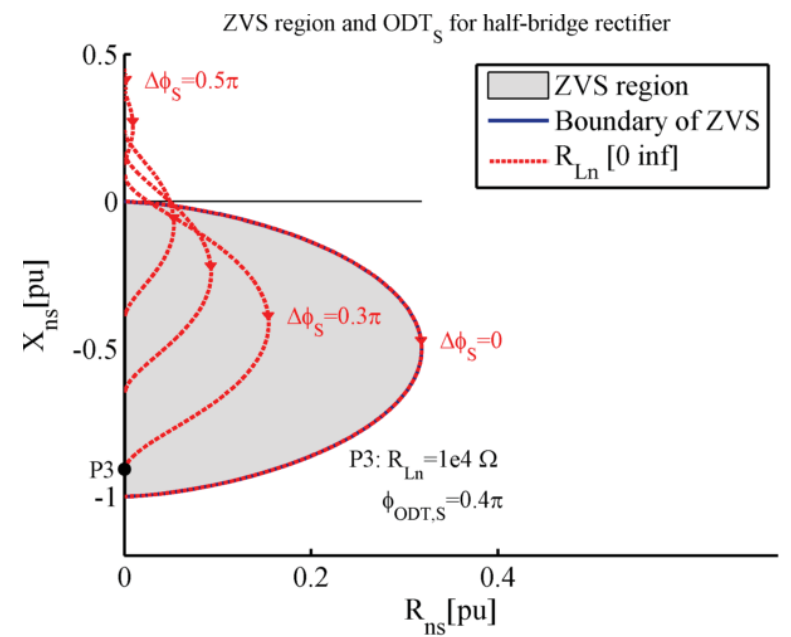

(a) Map of points with different phase shift in the full range of the load

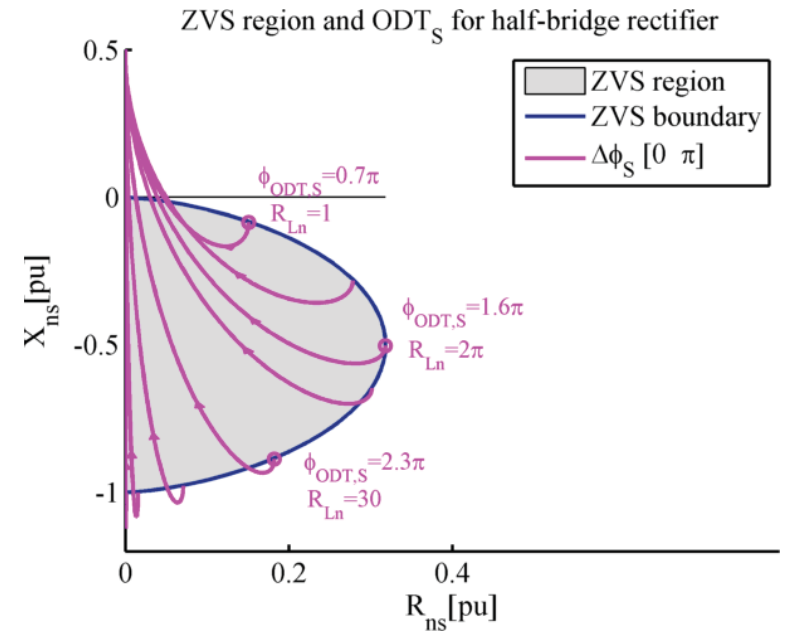

(b) Map of points with different normalized load values.

Fig. 12: ZVS region for the rectifier network.

\section{Rectifier's results}

Fig. 12 shows the rectifier's ZVS region and its boundary in the NELIP plane. The subfigure at the bottom of the figure shows curves when the $R_{L}$ is fixed to one value and the locus of points with different $\Delta \phi_{s}$. For instance, if the load resistance is $R_{L n}=2 \pi$, the phase related to the optimum DT can be in the range of $\phi_{O D T, S}=[1.5 \pi, 1.6 \pi]$ for the points inside the ZVS region. The subfigure on the top of the figure shows the locus of points with different load resistance where $\Delta \phi_{O D T, S}$ is fixed to a certain value and the normalized load varies. The point $P_{3}$ is located on the curve where $\Delta \phi_{S}=0.3 \pi, R_{L n}=10 \mathrm{k} \Omega$, and $\phi_{O D T, S}=0.4 \pi$. Experimental results are shown in Fig. 13, for PT-based converters with resistive load and half-bridge rectifier. In each case, two operating points are considered where the inverter's switches have soft switching and hard switching. The related parameters for these four operating points are measured and mapped to the inverter's NELIP plane in Fig. 14. The experimets show matched results with the analysis. Results in Figs. 12 and 13 show that operating points 
for which ZVS is obtained are located inside the ZVS region and the operating points for which ZVS is not attained (hard switching), are located outside the ZVS region.

\section{ZVS region of the converter}

Fig. 15 shows the equivalent circuit seen from the primary side of the converter, where $C_{P e}=C C_{S} /\left(n^{2} C+C_{S}\right)$ and $R_{P e}=$ $R+n^{2} R_{s}$. Therefore,

$$
Z_{P e}=R_{P e}+X_{P e}=R_{P e}+j\left(\omega L-\frac{1}{\omega C_{P e}}\right)
$$

The $Z_{P e}$ can be mapped into the NELIP to show whether or not the ZVS can be attained. In order to find $R_{P e}$ the topology of the converter should be considered. Furthermore, the operating frequency of the converter has a significant effect on the mapped ZVS region, which is from the rectifier to the inverter NELIP plane. This method is used to define the common area between the two ZVS regions. The overlapping area shows that soft switching can be obtained for the inverter's and rectifier's switches (related to $v_{F P}$ and $v_{F S}$ ) for the operating points located inside this particular area. In some other areas, the ZVS region can be obtained for either $v_{F S}$ or $v_{F P}$ or non of them. Fig. 16a shows the mapped ZVS region of the rectifier to the inverter's NELIP plane. The rectifier's ZVS region is mapped to the primary-side of the converter for two different frequencies, $f_{\text {res }}$ and $1.02 f_{\text {res }}$, where $f_{\text {res }}$ is the transformer's resonant frequency utilized in all the experiments. It shows that the overlapping region where ZVS can be obtained for both the inverter and the rectifier network varies in terms of operating frequency, which is expected. Fig. 16b shows the ZVS regions for the operating point $P_{2}$ demonstrated in Fig. 10 for which the switching frequency is $114.8 \mathrm{kHz}$. The point $P_{2}$ is situated inside the common area of the ZVS regions and it is shown in Fig. 10.The Flowchart shown in Fig. 17 shows a simple step by step design procedure for obtaining ZVS for all switches based on the presented analysis. This suggested design procedure is applicable for the cases where there is access to measure or detect the resonant current's amplitude and phase.

\section{CONCLUSION}

This paper has proposed a new method of analysis to find ZVS regions for the inverter and the rectifier networks inside the PT-based SMPS. Comprehensive equations were provided for the first time and were proven by simulation and experimental results. Experiments showed mapped operating points for inductorless PT-based converters in the NELIP plane. Furthermore, this analysis estimates the possibility of ZVS achievement and optimum DT for different operating points in terms of load variations both for the inverter and the rectifier networks. In practice providing a condition for attaining ZVS in all switches is a challenging task. Therefore, the work has further presented guidelines to find the region where all the converter's switches have soft switching. The proposed method is generally applicable for any type of resonant converter, but details are described for inductorless PT-based converters.

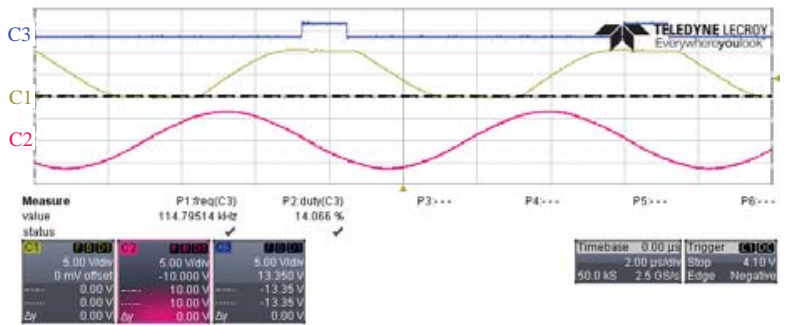

(a) Converter with resistive load and soft switching, related to the point $P_{7}$ in Fig. 14. $f_{\text {res }}=114.8 \mathrm{kHz} . \mathrm{C}_{1}$ : The switching voltage $v_{F P} ; \mathrm{C}_{2}$ : Resonant current; $\mathrm{C}_{3}$ : The gate voltage of $\mathrm{S} 1$.

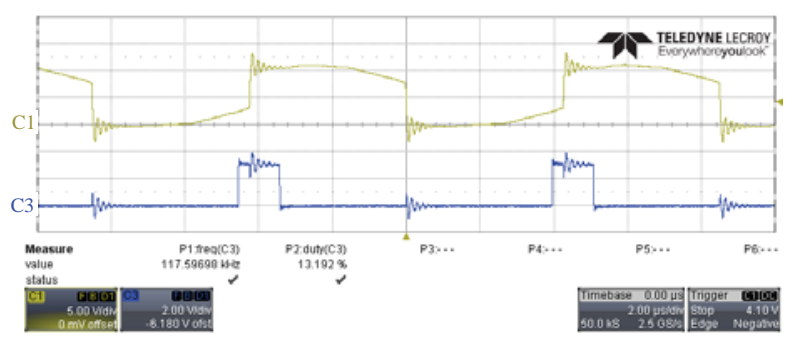

(b) Converter with resistive load and hard switching, related to the point $P_{6}$ in Fig. 14. $f_{\text {res }}=117.6 \mathrm{kHz}$. $\mathrm{C}_{1}$ : The switching voltage $v_{F P} ; \mathrm{C}_{3}$ : The gate voltage of $\mathrm{S} 1$.

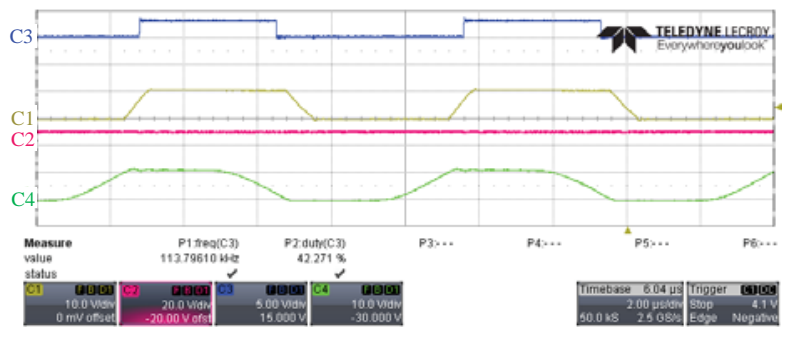

(c) Converter with rectifier network and soft switching, related to the point $P_{5}$ in Fig. 14. $f_{\text {res }}=113.8 \mathrm{kHz} . \mathrm{C}_{1}$ : The switching voltage $v_{F P} ; \mathrm{C} 2$ : The output voltage $V_{o}=10 \mathrm{~V} ; \mathrm{C}_{3}$ : The gate voltage of $\mathrm{S} 1 ; \mathrm{C}_{4}$ : The switching voltage $v_{F S}$

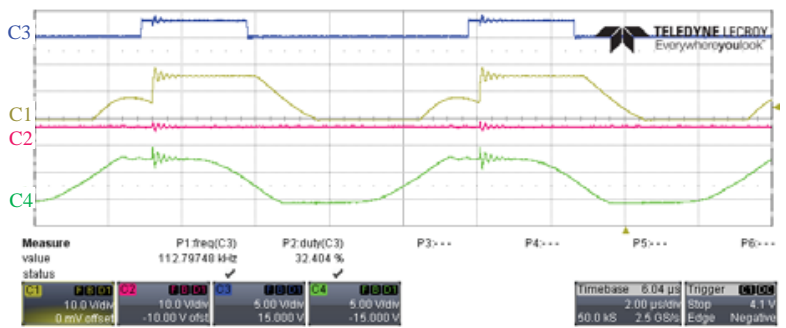

(d) Converter with rectifier network and hard switching, related to the point $P_{4}$ in Fig. 14. $f_{\text {res }}=112.8 \mathrm{kHz} . \mathrm{C}_{1}$ : The switching voltage $v_{F P} ; \mathrm{C}_{2}$ : The output voltage $V_{o}=10 \mathrm{~V} ; \mathrm{C}_{3}$ : The gate voltage of $\mathrm{S} 1 ; \mathrm{C}_{4}$ : The switching voltage $v_{F S}$.

Fig. 13: Four operating points for PT-based converter; (a): converter has resistive load attained soft switching; (b): converter has resistive load with hard switching; (c): converter has rectifier network attained soft switching; (d): converter has rectifier network with hard switching. 


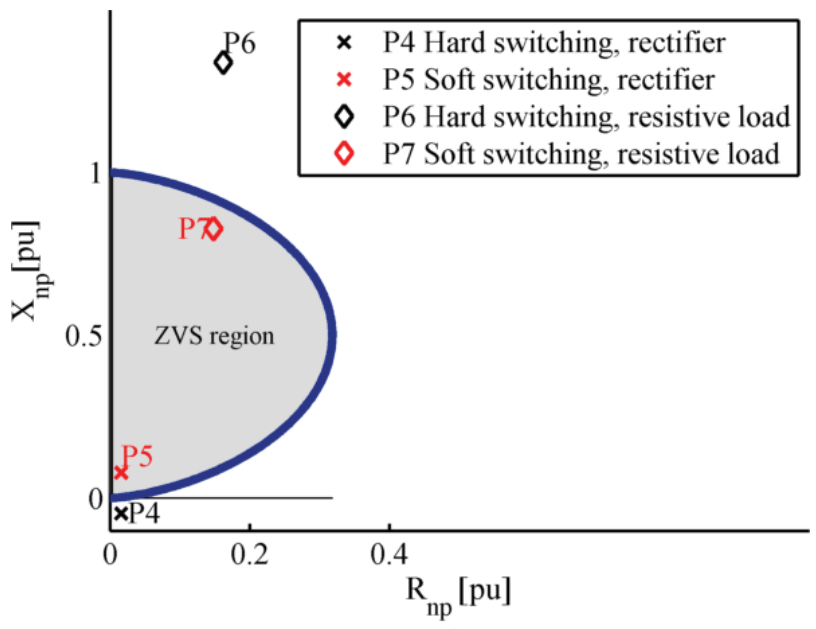

Fig. 14: Mapping of the four operating points shown in Fig. 13.

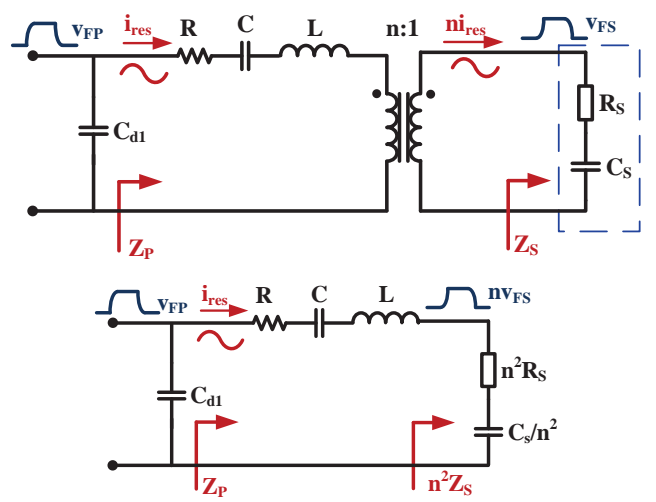

Fig. 15: Equivalent impedances of the converter seen from the inverter.

\section{APPENDIX}

\section{A. Deriving $Z_{n s}$ for the rectifier}

During the dead time period when the resonant current is positive and charges the output capacitor from the negative rail to the positive rail, $v_{F S}$ is described as:

$$
v_{F S}\left(t^{\prime}\right)=v_{F S}\left(0^{-}\right)+\frac{1}{C_{\text {out }}} \int_{\Delta \phi_{s}}^{\omega t^{\prime}} n I_{\text {res }}(t) d \omega t^{\prime}
$$

The voltage across the output capacitor reaches the positive rail $v_{F S}=\frac{V_{0}}{2}$ at $\omega t^{\prime}=\Delta \phi_{S}+\phi_{O D T, S}$. Thereby, $V_{o}$ is found as:

$$
V_{0}=\frac{n I_{p k}}{\omega C_{\text {out }}}\left(\cos \left(\Delta \phi_{s}\right)-\cos \left(\Delta \phi_{s}+\phi_{O D T, S}\right)\right)
$$

The resonant current goes to the output in the period that highside switch, $S 3$, is on, and the average of the current appears to the output:

$$
<I_{\text {out }}>=\frac{n I_{p k}}{2 \pi}\left[\cos \left(\Delta \phi_{s}+\phi_{O D T, S}\right)+\cos \left(\Delta \phi_{S}\right)\right]
$$

the output voltage is constant; therefor, the output current goes through the load resistance $\left.V_{o}=R_{L}<I_{\text {out }}\right\rangle$, which yields:

$$
\cos \left(\Delta \phi_{S}+\phi_{O D T, S}\right)=\frac{2 \pi-R_{L n}}{2 \pi+R_{L n}} \cos \left(\Delta \phi_{S}\right)
$$

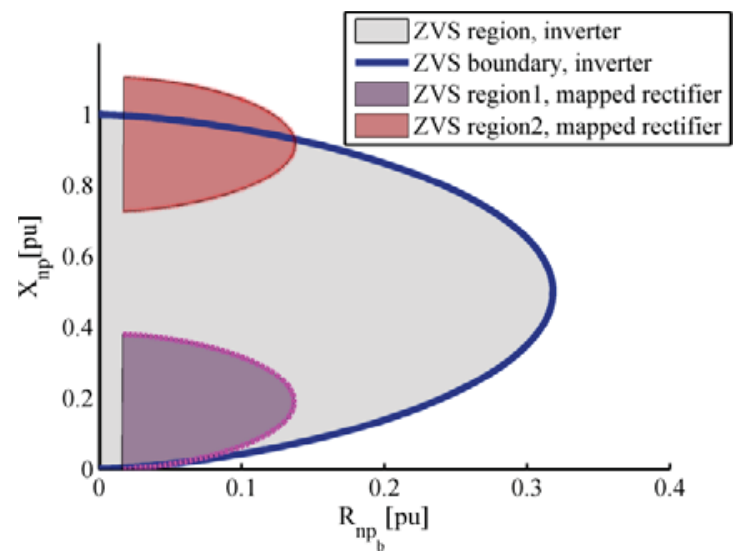

(a) The mapped rectifier's ZVS region for different switching frequencies.

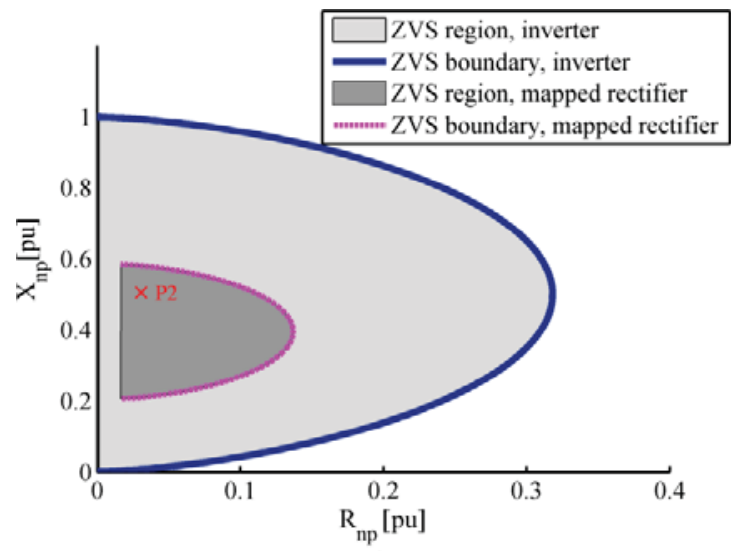

(b) The mapped rectifier's ZVS region for the switching frequency of $114.8 \mathrm{kHz}$.

Fig. 16: ZVS regions of the rectifier and the inverter seen from the inverter's side.

where $R_{L n}=\omega R_{L} C_{\text {out }}$ is a normalized load resistance. Substituting Equation (34) into Equations (33) and (32) results in:

$$
<I_{\text {out }}>=\frac{2 n I_{p k} \cos \left(\Delta \phi_{s}\right)}{2 \pi+R_{L n}}
$$

The equivalent resistor and capacitor are found as

$$
R_{s}=\frac{8 R_{L} \cos ^{2}\left(\Delta \phi_{S}\right)}{\left(2 \pi+R_{L n}\right)^{2}}
$$

$$
\begin{gathered}
C_{s}=\frac{\pi \mathrm{C}_{\mathrm{out}}\left(2 \pi+R_{L n}\right)^{2}}{\cos \left(\Delta \phi_{S}\right)\left(2 \pi-R_{L n}\right) A+\left(2 \pi+R_{L n}\right)^{2}\left(\phi_{O D T, S}+\sin \left(2 \Delta \phi_{s}\right)\right)} \\
A=\left(2 \pi+R_{L n}\right) \sqrt{1-\left(\frac{2 \pi-R_{L n}}{2 \pi+R_{L n}}\right)^{2} \cos ^{2}\left(\Delta \phi_{S}\right)} \\
\phi_{O D T, S}=\cos ^{-1}\left(\frac{2 \pi-R_{L n}}{2 \pi+R_{L n}}\right) \cos \left(\Delta \phi_{s}\right)-\Delta \phi_{s}
\end{gathered}
$$

This then yields the normalized impedances $Z_{n s}=R_{n s}+j X_{n s}$ by multiplying $\omega C_{\text {out }}$ with the $R_{S}$ and $X_{S}$

$$
Z_{n s}=\omega C_{o u t} Z_{S}=R_{n s}+j X_{n s}
$$




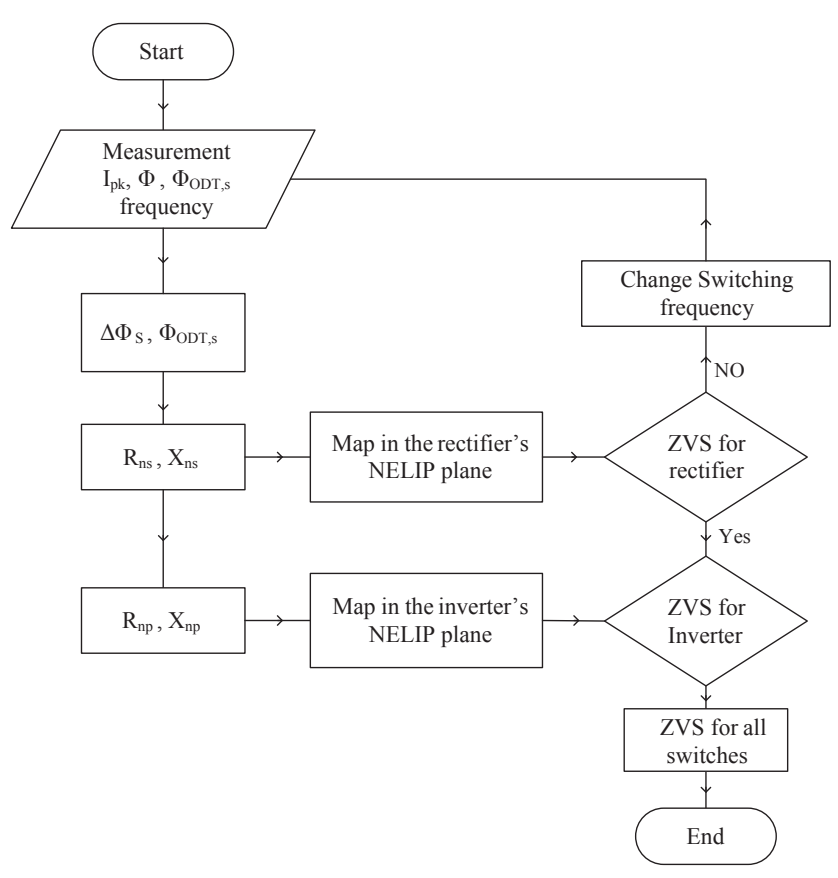

Fig. 17: A step by step design method applicable where there is access to dynamically measure the resonant current.

Note that $R_{S}$ and $C_{S}$ depends on $R_{L n}$ where $R_{L n}$ depends on $\omega$ and load resistance $R_{L}$.

\section{B. Deriving $Z_{n p}$ for the inverter}

Fig. 6 shows waveforms of the voltage $v_{F P}$ and the resonant current $i_{\text {res. }}$. In the time slot, $0 \leq \omega t \leq \omega t_{O D T, P} ; i_{C_{i n}}=-i_{\text {res }}$, then $v_{F P}$ is found as

$$
\left.v_{F P}(t)=\frac{I_{p k}}{\omega C_{i n}} \cos (\omega t-\phi)-\cos (\phi)\right)-\frac{V_{D C}}{2}
$$

At $\omega t=\phi_{O D T, P}$, the switching voltage reaches the positive rail. Therefore, $v_{F P}\left(\phi_{O D T, P}\right)=\frac{V_{D C}}{2}$, which yields

$$
\left.v_{F P}=\frac{V_{D C}}{2}=\frac{I_{p k}}{\omega C_{i n}} \cos (\omega t-\phi)-\cos (\phi)\right)-\frac{V_{D C}}{2}
$$

Solving above equation for $I_{p k}$ gives

$$
I_{p k}=\frac{V_{D C} \omega C_{i n}}{\cos \left(\phi_{O D T, P}-\phi\right)-\cos (\phi)}
$$

Substituting Equation (40) into Equations (9) and (39) results in a general equation of $i_{\text {res }}$ and $v_{F P}$ :

$$
\begin{aligned}
i_{r e s}(t)= & \left(\frac{V_{D C} \omega C_{i n}}{\cos \left(\phi_{O D T, P}-\phi\right)-\cos (\phi)}\right) \sin (\omega t-\phi) 0 \leq \omega t \leq 2 \pi \\
v_{F P}(t)= & \frac{V_{D C}}{2\left[\cos \left(\phi_{O D T, P}-\phi\right)-\cos (\phi)\right]} \quad 0 \leqslant \omega t \leqslant \phi_{O D T, P} \\
& {\left[2 \cos (\omega t-\phi)-\cos \left(\phi_{O D T, P}-\phi\right)-\cos (\phi)\right] }
\end{aligned}
$$

The fundamental components of $v_{F P}(t)$ and $i_{\text {res }}(t)$ can be found by Fourier analysis. The corresponding phasor represen- tation of $v_{F P}(t)$ for the fundamental component of the Fourier series is

$$
\begin{aligned}
\left(\bar{V}_{F P}\right)_{1}= & \frac{1}{\pi} \frac{V_{D C}}{\left[\cos \left(\phi_{O D T, P}-\phi\right)-\cos (\phi)\right]} \quad 0 \leqslant \omega t \leqslant 2 \pi \\
& {\left[\frac{-1}{2} \sin \left(2 \phi_{O D T, P}-\phi\right)-\frac{1}{2} \sin (\phi)\right.} \\
& +\phi_{O D T, P}(\cos (\phi)-j \sin (\phi)) \\
& \left.\frac{1}{2} j \cos \left(2 \phi_{O D T, P}-\phi\right)+\frac{1}{2} j \cos (\phi)\right]
\end{aligned}
$$

Therefore, the fundamental component of the resonant current is represented by the phasor

$$
\begin{gathered}
\left(\bar{I}_{\text {res }}\right)_{1}=\frac{-V_{D C} \omega C_{\text {in }}}{\cos \left(\phi_{O D T, P}-\phi\right)-\cos (\phi)}[\sin (\phi)+j \cos (\phi)] \\
0 \leqslant \omega t \leqslant 2 \pi
\end{gathered}
$$

The effective equivalent impedance seen by the switching network is $Z_{P}=\left(\bar{V}_{F P}\right)_{1} /\left(\bar{I}_{\text {res }}\right)_{1}=R_{P}+j X_{P}$. Normalizing $Z_{P}$ by multiplying by $\omega C_{i n}$ results in $Z_{n p}$ as below.

$$
Z_{n p}=\omega C_{i n} Z_{P}=\omega C_{i n} \frac{\bar{V}_{F}}{\bar{I}_{\text {res }}}=R_{n p}+j X_{n p}
$$

\section{ACKNOWLEDGMENT}

The authors would like to thank Noliac A/S for supplying prototype of piezoelectric transformers as well as "The Danish National Advanced Technology Foundation" for their financial support.

\section{REFERENCES}

[1] E. M. Baker, W. Huang, D. Y. Chen, and F. C. Lee, "Radial mode piezoelectric transformer design for fluorescent lamp ballast applications," Power Electronics, IEEE Transactions on, vol. 20, no. 5, pp. 1213-1220, 2005.

[2] S. Ben-Yaakov and S. Lineykin, "Maximum power tracking of piezoelectric transformer hv converters under load variations," Power Electronics, IEEE Transactions on, vol. 21, no. 1, pp. 73-78, 2006.

[3] J. Díaz, F. Nuño, M. J. Prieto, J. Martín-Ramos, P. J. V. Saiz et al., "Closing a second feedback loop in a dc-dc converter based on a piezoelectric transformer," Power Electronics, IEEE Transactions on, vol. 22, no. 6, pp. 2195-2201, 2007.

[4] A. V. Carazo, "50 years of piezoelectric transformers: Trends in the technology," Materials research society symposium proceedings, vol. 785, pp. 33-46, 2004.

[5] M. Rodgaard, T. Andersen, and M. A. Andersen, "Empiric analysis of zero voltage switching in piezoelectric transformer based resonant converters," 6th IET International Conference on Power Electronics, Machines and Drives (PEMD 2012), 2012.

[6] J. M. Alonso, C. Ordiz, M. Dalla Costa, J. Ribas, J. Cardesín et al., "High-voltage power supply for ozone generation based on piezoelectric transformer," Industry Applications, IEEE Transactions on, vol. 45, no. 4, pp. 1513-1523, 2009.

[7] E. M. Baker, "Design of radial mode piezoelectric transformers for lamp ballast applications," Ph.D. dissertation, Virginia Polytechnic Institute and State University, 2002.

[8] G. Ivensky, S. Bronstein, and S. S. Ben-Yaakov, "A comparison of piezoelectric transformer ac/dc converters with current doubler and voltage doubler rectifiers," Power Electronics, IEEE Transactions on, vol. 19, no. 6, pp. 1446-1453, 2004.

[9] M. Ekhtiari, "Nonmagnetic driver for piezoelectric actuators," ICECS 2014, 21st IEEE International Conference on Electronics Circuits and Systems, 2014.

[10] R. L. Lin, F. C. Lee, E. M. Baker, and D. Y. Chen, "Inductor-less piezoelectric transformer electronic ballast for linear fluorescent lamp," Applied Power Electronics Conference and Exposition, 2001. APEC 2001. Sixteenth Annual IEEE, vol. 2, pp. 664-669, 2001. 
[11] S. Bronstein and S. Ben-Yaakov, "Design considerations for achieving zvs in a half bridge inverter that drives a piezoelectric transformer with no series inductor," Power Electronics Specialists Conference, 2002. pesc 02. 2002 IEEE 33rd Annual, vol. 2, pp. 585-590, 2002.

[12] M. Sanz, P. Alou, A. Soto, R. Prieto, J. Cobos, and J. Uceda, "Magneticless converter based on piezoelectric transformers for step-down $\mathrm{dc} / \mathrm{dc}$ and low power application," Applied Power Electronics Conference and Exposition, 2003. APEC'03. Eighteenth Annual IEEE, vol. 2, pp. 615 $621,2003$.

[13] E. Horsley, M. Foster, and D. Stone, "State-of-the-art piezoelectric transformer technology," Power Electronics and Applications, 2007 European Conference on, pp. 1-10, 2007.

[14] R. Erickson and D. Maksimović, Fundamentals of Power Electronics. NewYork: KluwerAcademic Publishers, Second edition 2001.

[15] M. Foster, H. Sewell, C. Bingham, D. Stone, and D. Howe, "Methodologies for the design of LCC voltage-output resonant converters," IEE Proceedings- Electric Power Applications, , vol. 153, no. 4, pp. 559-567, July 2006.

[16] F. E. Bisogno, M. Radecker, A. Knoll, A. V. Carazo, A. Riedlhammer, G. Deboy, N. Norvez et al., "Comparison of resonant topologies for stepdown applications using piezoelectric transformers," Power Electronics Specialists Conference, PESC04, 2004 IEEE 35th Annual, vol. 4, pp. 2662-2667, 2004

[17] Y. Yang, F. E. Bisogno, A. Schittler, S. Nittayarumphong, M. Radecker, W.-J. Fischer, and M. Fahlenkamp, "Comparison of inductor-half-bridge and class-E resonant topologies for piezoelectric transformer applications," Energy Conversion Congress and Exposition, 2009. ECCE 2009. IEEE, pp. 776-782, 2009.

[18] E. L. Horsley, "Modelling and analysis of radial mode piezoelectric transformers and inductor-less resonant power converters," $\mathrm{Ph}$.D. dissertation, University of Sheffield, 2011.

[19] M. P. Foster, E. Horsley, and D. Stone, "Predicting the zero-voltage switching profiles of half-bridge driven inductor-less piezoelectric transformer-based inverters," IET Power Electronics, vol. 5, no. 7, pp. 1068-1073, 2012.

[20] E. Horsley, A. Carazo, N. Nguyen-Quang, M. Foster, and D. Stone, "Analysis of inductorless zero-voltage-switching piezoelectric transformer-based converters," Power Electronics, IEEE Transactions on, vol. 27, no. 5, pp. 2471-2483, 2012.

[21] W.-C. Su and C.-L. Chen, "ZVS for PT backlight inverter utilizing high-order current harmonic," Power Electronics, IEEE Transactions on, vol. 23, no. 1, pp. 4-10, 2008.

[22] E. Horsley, N. Nguyen-Quang, M. Foster, and D. Stone, "Achieving ZVS in inductor-less half-bridge piezoelectric transformer based resonant converters," PEDS, pp. 446-451, 2009.

[23] M. S. Rodgaard, M. A. Andersen, and E. Bruun, "Piezoelectric transformer based power converters; design and control," Ph.D. dissertation, Technical University of Denmark, 2012.

[24] R.-L. Lin, "Piezoelectric transformer characterization and application of electronic ballast," Ph.D. dissertation, Virginia Polytechnic Institute and State University, 2001

[25] K. S. Meyer, M. A. Andersen, and F. Jensen, "Parameterized analysis of zero voltage switching in resonant converters for optimal electrode layout of piezoelectric transformers," Power Electronics Specialists Conference, 2008. PESC 2008. IEEE, pp. 2543-2548, 2008.

[26] M. Ekhtiari, Z. Zhang, and M. A. E. Andersen, "State-of-the-art piezoelectric transformer-based switch mode power supplies," Industrial Electronics Society, IECON 2014-40th Annual Conference of the IEEE, pp. 5072-5078, 2014.

[27] C. yi Lin, "Design and analysis of piezoelelctric transformer converters," Ph.D. dissertation, 1997.

[28] M. S. Rodgaard, "Bi-directional piezoelectric transformer based converter for high-voltage capacitive applications," Applied Power Electronics Conference and Exposition (APEC), 2015 IEEE, pp. 1993-1998, 2015.

[29] D. C. Hamill, "Class DE inverters and rectifiers for DC-DC conversion," Power Electronics Specialists Conference, PESC'96 Record., 27th Annual IEEE, vol. 1, pp. 854-860, 1996.

[30] J. G. Hayes and M. G. Egan, "Rectifier-compensated fundamental mode approximation analysis of the series parallel lclc family of resonant converters with capacitive output filter and voltage-source load," Power Electronics Specialists Conference, 1999. PESC 99. 30th Annual IEEE, vol. 2, pp. 1030-1036, 1999.

[31] W. P. Mason, Electromechanical transducers and wave filters. D. Van Nostrand Co., 1948.

[32] T. Andersen, M. A. Andersen, and O. C. Thomsen, "Simulation of piezoelectric transformers with comsol," COMSOL conference, 2012.

[33] G. Zerong, J. Lingling, L. Huabo, and W. Ting, "Measurement of pt equivalent circuit model parameters based on admittance circle," Mechatronic Science, Electric Engineering and Computer (MEC), 2011 International Conference on, pp. 20-23, 2011.

[34] X.-c. Chu, J.-f. Wu, Z.-h. Xu, and L.-t. Li, "Experiment research on multilayer piezoelectric transformer," Piezoelectricity, Acoustic Waves, and Device Applications, 2008. SPAWDA 2008. Symposium on, pp. 524527, 2008.

[35] A. V. Mezheritsky, "Quality factor concept in piezoceramic transformer performance description," Ultrasonics, Ferroelectrics, and Frequency Control, IEEE Transactions on, vol. 53, no. 2, pp. 429-442, 2006.

[36] D. Hamill, "Half bridge class DE rectifier," Electronics Letters, vol. 31, no. 22, pp. 1885-1886, 1995. 